\title{
Is Limb Salvage With Microwave-induced Hyperthermia Better Than Amputation for Osteosarcoma of the Distal Tibia?
}

\author{
Kang Han MD, PhD, Peiye Dang MS, Na Bian MS, \\ Xiang Chen MD, PhD, Tongtao Yang MD, PhD, QingYu Fan MD, PhD, \\ Yong Zhou MD, PhD, Tingbao Zhao MD, PhD, Pingshan Wang MD, PhD
}

Received: 22 September 2016/ Accepted: 27 January 2017/Published online: 13 February 2017

(C) The Author(s) 2017. This article is published with open access at Springerlink.com

\begin{abstract}
Background Amputation has been the standard surgical treatment for distal tibia osteosarcoma owing to its unique anatomic features. Preliminary research suggested that
\end{abstract}

The institution of one author $(\mathrm{KH})$ has received, during the study period, funding from the president funding of General Hospital of Jinan Military Area Command of Chinese PLA (Grant\# 2015ZX01; $\mathrm{KH})$.

Each author certifies that he or she, or a member of his or her immediate family, has no funding or commercial associations (eg, consultancies, stock ownership, equity interest, patent/licensing arrangements, etc) that might pose a conflict of interest in connection with the submitted article.

All ICMJE Conflict of Interest Forms for authors and Clinical Orthopaedics and Related Research ${ }^{\mathbb{R}}$ editors and board members are on file with the publication and can be viewed on request.

Each author certifies that his or her institution approved the human protocol for this investigation, that all investigations were conducted in conformity with ethical principles of research, and that informed consent for participation in the study was obtained.

K. Han ( $₫)$, N. Bian, T. Zhao, P. Wang

Department of Spinal Cord Injury, General Hospital of Jinan

Military Area Command of Chinese PLA, Jinan 250000,

Shandong, People's Republic of China

e-mail: gan_7758525@163.com; 33672764@qq.com

P. Dang

Department of Orthopedic Surgery Center, Xingyuan Hospital, Yulin, Shaanxi, People's Republic of China

X. Chen

Department of Pediatrics, Baylor College of Medicine, Houston, TX 77030, USA

T. Yang, Q. Fan, Y. Zhou

Department of Orthopedic Surgery, Orthopedics Oncology Institute of Chinese PLA, Tangdu Hospital, Fourth Military

Medical University, Xi'an, Shaanxi, People's Republic of China microwave-induced hyperthermia may have a role in treating osteosarcoma in some locations of the body (such as the pelvis), but to our knowledge, no comparative study has evaluated its efficacy in a difficult-to-treat location like the distal tibia.

Questions Does microwave-induced hyperthermia result in (1) improved survival, (2) decreased local recurrence, (3) improved Musculoskeletal Tumor Society (MSTS) scores, or (4) fewer complications than amputation in patients with a distal tibial osteosarcoma?

Methods Between 2000 and 2015, we treated 79 patients for a distal tibia osteosarcoma without metastases. Of those, 52 were treated with microwave-induced hyperthermia, and 27 with amputation. Patients were considered eligible for microwave-induced hyperthermia if they had an at least $20-\mathrm{mm}$ available distance from the tumor edge to the articular surface, good clinical and imaging response to neoadjuvant chemotherapy, and no pathologic fracture. Patients not meeting these indications were treated with amputation. In addition, if neither the posterior tibial artery nor the dorsalis pedis artery was salvageable, the patients were treated with amputation and were not included in any group in this study. A total of 13 other patients were treated with conventional limb-salvage resections and reconstructions (at the request of the patient, based on patient preference) and were not included in this study. All 79 patients in this retrospective study were available for followup at a minimum of 12 months (mean followup in the hyperthermia group, 79 months, range 12-158 months; mean followup in the amputation group, 95 months, range, 15-142 months). With the numbers available, the groups were no different in terms of sex, age, tumor grade, tumor stage, or tumor size. All statistical tests were two-sided, and a probability less than 0.05 was considered statistically significant. Survival to death was evaluated using Kaplan- 
Meier analysis. Complications were recorded from the patients' files and graded using the classification of surgical complications described by Dindo et al.

Results In the limb-salvage group, Kaplan Meier survival at 6 years was $80 \%$ (95\% CI, 63\%-90\%), and this was not different with the numbers available from survivorship in the amputation group at 6 years $(70 \%$; $95 \%$ CI, 37\%-90\%; $\mathrm{p}=0.301$ ). With the numbers available, we found no difference in local recurrence (six versus $0 ; p=0.066$ ). However mean \pm SD MSTS functional scores were higher in patients who had microwave-induced hyperthermia compared with those who had amputations $(85 \% \pm 6 \%$ versus $66 \% \pm 5 \% ; \mathrm{p}=0.008$ ). With the numbers available, we found no difference in the proportion of patients experiencing complications between the two groups (six of 52 [12\%] versus three of 27 [11\%]; $p=0.954$ ).

Conclusions We were encouraged to find no early differences in survival, local recurrence, or serious complications between microwave-induced hyperthermia and amputation, and a functional advantage in favor of microwave-induced hyperthermia. However, these findings should be replicated in larger studies with longer mean duration of followup, and in studies that compare microwave-induced hyperthermia with conventional limbsparing approaches.

Level of Evidence Level III, therapeutic study.

\section{Introduction}

The tibia is the second most-common site of osteosarcoma, accounting for $19 \%$ of all osteosarcomas, with $20 \%$ of those occurring in the distal tibia [22]. Amputation has long been regarded as the standard surgical treatment for these tumors, with satisfactory functional results when an appropriate prosthesis is used [25]. With the advances in chemotherapy and surgical techniques, limb salvage has become the preferred treatment when possible. However, other than in locations like those surrounding the hip or knee, it is difficult to perform a safe, negative-margin resection in the distal tibia because of its subcutaneous location and the proximity of the distal tibia to the neurovascular bundle and tendons [18]. Complications, poor function, and decreased durability of the reconstruction are difficult to avoid in this location [19].

Conflicting findings regarding survival and function after limb salvage and amputation for patients with osteosarcoma of the distal tibia have been reported $[2,4,15,19,20,26]$. While survivorship of patients who undergo amputation for distal tibia osteosarcoma generally is high [26] and complications are disconcertingly frequent [4], function as measured by the Musculoskeletal Tumor
Society (MSTS) [6] score after amputation is generally low [15]. Small series of patients undergoing limb salvage for osteosarcoma in this location are not always dramatically better in terms of function [20], complications are likewise common [25], and survivorship seems even worse [18]. For this reason, we believe the best surgical option for patients who have osteosarcoma of the distal tibia is unclear.

Hyperthermia has been introduced as an alternative treatment method for osteosarcoma [8]. It is capable of accurately killing tumor cells while tending to minimize injury to the surrounding tissue, perhaps facilitating resections in difficult-to-access locations. Hyperthermia can be used to achieve acceptable local disease control while maintaining the structural integrity of the skeleton in some patients [9]. This technique may reduce the need for complex reconstruction, and so seems appealing in terms of potential functional benefits; however, this is unproven for patients with osteosarcoma of the distal tibia. In this setting, microwave-induced hyperthermia is administered to the tumor bed and causes immediate heat necrosis of the tumor and adjacent tissues, followed by limited surgical excision of the mass with preservation of the surrounding skeleton. Because of its perceived benefits, we have used microwave-induced hyperthermia in patients with malignant bone tumors for 20 years in our department [7, 8]; however, no formal study has compared microwave-induced hyperthermia with the conventional treatment (transtibial amputation), and it seems important to do so.

We therefore asked: Does microwave-induced hyperthermia result in (1) improved survival, (2) decreased local recurrence, (3) improved MSTS scores, or (4) fewer complications than amputation in patients with a distal tibial osteosarcoma?

\section{Patients and Methods}

The research was approved by the Ethics Review Committee of Tangdu Hospital, Xian, Shanxi, China (approval ID 2016016), and written informed consent was obtained from all participating patients.

\section{Cohort Selection}

Between 2000 and 2015, we treated 106 patients for distal tibia osteosarcoma without metastases. Of those, 52 were treated with microwave-induced hyperthermia (Table 1), and 41 with amputation. A total of 13 patients who would have met our indications for microwave-induced hyperthermia were instead treated with the conventional limbsalvage resection and reconstruction based on the patient's 
Table 1. Details of the patients with distal tibia osteosarcoma who had microwave-induced hyperthermia

\begin{tabular}{|c|c|c|c|c|}
\hline $\begin{array}{l}\text { Patient number/ } \\
\text { gender/age (years) }\end{array}$ & $\begin{array}{l}\text { AJCC } \\
\text { stage }\end{array}$ & $\begin{array}{l}\text { Histology/ } \\
\text { Broders' grade }\end{array}$ & $\begin{array}{l}\text { Tumor } \\
\text { size }\left(\mathrm{cm}^{2}\right)\end{array}$ & Chemotherapy \\
\hline $1 / \mathrm{F} / 31$ & IIA & 3 & 11.6 & + \\
\hline 2/M/9 & IIA & 4 & 8.8 & + \\
\hline $3 / \mathrm{M} / 28$ & IIB & 4 & 9.5 & + \\
\hline $4 / \mathrm{F} / 20$ & IB & 3 & 12.3 & + \\
\hline $5 / F / 33$ & IIA & 4 & 4.6 & + \\
\hline $6 / \mathrm{M} / 25$ & IIB & 2 & 13.6 & + \\
\hline $7 / \mathrm{F} / 53$ & IB & 4 & 12.8 & + \\
\hline $8 / \mathrm{M} / 26$ & IIA & 4 & 11.6 & + \\
\hline 9/M/50 & IB & 1 & 9.1 & + \\
\hline 10/F/12 & IIB & 4 & 20.6 & \\
\hline $11 / \mathrm{M} / 21$ & IIA & 2 & 12.5 & + \\
\hline $12 / F / 23$ & IB & 4 & 15.2 & + \\
\hline $13 / \mathrm{M} / 32$ & IIA & 2 & 11.4 & + \\
\hline $14 / F / 25$ & IIB & 4 & 12.5 & + \\
\hline $15 / F / 23$ & IB & 1 & 7.8 & + \\
\hline $16 / \mathrm{M} / 34$ & IIA & 4 & 6.6 & + \\
\hline $17 / \mathrm{M} / 23$ & IIB & 3 & 13.2 & + \\
\hline $18 / \mathrm{F} / 44$ & IB & 4 & 14.6 & + \\
\hline 19/M/39 & IIB & 1 & 15.1 & + \\
\hline $20 / \mathrm{F} / 40$ & IIB & 4 & 12.3 & + \\
\hline 21/M/38 & IA & 4 & 8.9 & + \\
\hline 22/M/18 & IIA & 2 & 9.7 & + \\
\hline $23 / F / 14$ & IIA & 4 & 6.8 & + \\
\hline $24 / \mathrm{M} / 20$ & IIB & 3 & 15.2 & + \\
\hline 25/M/30 & IIA & 2 & 9.4 & + \\
\hline $26 / M / 52$ & IA & 4 & 8.3 & + \\
\hline 27/F/8 & IIA & 4 & 8.1 & + \\
\hline $28 / \mathrm{M} / 32$ & IIA & 2 & 7.6 & + \\
\hline $29 / F / 23$ & IA & 4 & 15.5 & + \\
\hline $30 / \mathrm{M} / 27$ & IIA & 3 & 13.1 & + \\
\hline $31 / F / 20$ & IIB & 1 & 16.8 & + \\
\hline $32 / \mathrm{M} / 34$ & IIA & 4 & 8.7 & + \\
\hline $33 / F / 25$ & IIA & 3 & 13.3 & + \\
\hline $34 / \mathrm{M} / 20$ & IA & 2 & 4.2 & + \\
\hline $35 / \mathrm{M} / 44$ & IIB & 4 & 8.8 & + \\
\hline $36 / F / 27$ & IIA & 4 & 12.7 & + \\
\hline $37 / \mathrm{M} / 17$ & IIA & 1 & 21.2 & + \\
\hline $38 / F / 18$ & IIA & 4 & 12.6 & + \\
\hline $39 / \mathrm{M} / 25$ & IA & 3 & 5.3 & + \\
\hline $40 / F / 33$ & IIA & 4 & 15.6 & + \\
\hline 41/M/30 & IIA & 4 & 13.9 & + \\
\hline $42 / F / 24$ & IIA & 3 & 15.4 & + \\
\hline 43/M/30 & IA & 4 & 13.2 & + \\
\hline 44/M/45 & IIA & 4 & 12.5 & + \\
\hline $45 / F / 28$ & IIA & 3 & 15.2 & + \\
\hline 46/M/28 & IIA & 4 & 14.7 & + \\
\hline 47/F/12 & IA & 4 & 17.6 & + \\
\hline
\end{tabular}


Table 1. continued

\begin{tabular}{lllll}
\hline $\begin{array}{l}\text { Patient number/ } \\
\text { gender/age (years) }\end{array}$ & $\begin{array}{l}\text { AJCC } \\
\text { stage }\end{array}$ & $\begin{array}{l}\text { Histology/ } \\
\text { Broders'grade }\end{array}$ & $\begin{array}{l}\text { Tumor } \\
\text { size }\left(\mathrm{cm}^{2}\right)\end{array}$ \\
\hline $48 / \mathrm{M} / 21$ & IIA & 3 & 18.6 & Chemotherapy \\
$49 / \mathrm{M} / 34$ & IIA & 4 & 12.9 & + \\
$50 / \mathrm{M} / 27$ & IIA & 3 & 15.4 & + \\
$51 / \mathrm{F} / 27$ & IIA & 3 & 17.8 & + \\
$52 / \mathrm{M} / 40$ & IA & 3 & 16.2 & + \\
\hline
\end{tabular}

AJCC $=$ American Joint Committee on Cancer.

Table 2. Details of the patients with distal tibia osteosarcoma who had amputation

\begin{tabular}{|c|c|c|c|c|}
\hline Patient number/ gender/age (years) & AJCC stage & Histology/Broders' grade & Tumor size $\left(\mathrm{cm}^{2}\right)$ & Chemotherapy \\
\hline $1 / \mathrm{M} / 21$ & IIB & 4 & 10.4 & + \\
\hline $2 / \mathrm{M} / 42$ & IB & 2 & 8.4 & - \\
\hline $3 / \mathrm{M} / 34$ & IIB & 4 & 12.9 & + \\
\hline $4 / F / 26$ & IIB & 3 & 11.1 & + \\
\hline $5 / \mathrm{M} / 28$ & IIA & 3 & 9.2 & - \\
\hline $6 / F / 32$ & IIB & 3 & 8.5 & - \\
\hline 7/F/15 & IIA & 4 & 11.5 & + \\
\hline $8 / \mathrm{F} / 24$ & IIB & 4 & 10.6 & + \\
\hline 9/M/16 & IIB & 4 & 9.7 & - \\
\hline $10 / F / 35$ & IIB & 3 & 18.2 & \\
\hline $11 / \mathrm{F} / 34$ & IIA & 4 & 21.3 & + \\
\hline $12 / \mathrm{M} / 25$ & IIB & 4 & 13.2 & + \\
\hline 13/M/30 & IIA & 4 & 19.4 & + \\
\hline $14 / F / 33$ & IIA & 4 & 10.9 & + \\
\hline 15/M/27 & IIB & 4 & 19.3 & + \\
\hline $16 / F / 52$ & IIA & 4 & 12.7 & + \\
\hline 17/M/33 & IB & 3 & 11.2 & + \\
\hline $18 / \mathrm{F} / 30$ & IIB & 4 & 14.6 & + \\
\hline $19 / \mathrm{F} / 29$ & IB & 1 & 5.4 & + \\
\hline 20/M/13 & IIB & 4 & 17.2 & + \\
\hline 21/M/34 & IIA & 4 & 9.9 & + \\
\hline $22 / F / 21$ & IIB & 4 & 9.6 & - \\
\hline $23 / \mathrm{F} / 40$ & IB & 3 & 12.5 & + \\
\hline $24 / F / 25$ & IIB & 3 & 17.6 & + \\
\hline $25 / F / 27$ & IIA & 4 & 9.1 & + \\
\hline $26 / \mathrm{M} / 27$ & IB & 3 & 8.6 & - \\
\hline $27 / F / 30$ & IIB & 4 & 8.4 & - \\
\hline
\end{tabular}

AJCC $=$ American Joint Committee on Cancer.

preferences (which might have been driven by cost, perceived functional demand, or other factors); these patients were not included in this retrospective study. If neither the posterior tibial artery nor the dorsalis pedis artery was salvageable, patients were treated with amputation; these patients $(n=14)$ were not included in any group in this study. This left 27 patients with amputations available for our study (Table 2) and 79 patients available for the entire study. Patients were considered eligible for microwaveinduced hyperthermia if they had an at least $20 \mathrm{~mm}$ available distance from the tumor edge to the articular surface, good clinical (such as pain reduction) and imaging 
Table 3. Comparison of the clinical information, clinical efficacy, and incidence of complications between two groups

\begin{tabular}{|c|c|c|c|c|}
\hline Variable & Limb salvage $(\mathrm{n}=52)$ & Amputation $(\mathrm{n}=27)$ & $\mathrm{p}$ Value & Statistical test \\
\hline Sex (male:female) & $30: 22$ & $12: 15$ & 0.263 & Chi-square \\
\hline Age (years) & $27.5 \pm 8.7$ & $31.2 \pm 6.4$ & 0.586 & Student's t-test \\
\hline Tumor grade & & & 0.083 & Chi-square \\
\hline Grades 1 and 2 & 12 & 2 & & \\
\hline Grades 3 and 4 & 40 & 25 & & \\
\hline Tumor stage & & & 0.407 & Chi-square \\
\hline Stage IA or IB & 14 & 5 & & \\
\hline Stage IIA or IIB & 38 & 22 & & \\
\hline \multicolumn{5}{|l|}{ Tumor size } \\
\hline$\leq 8 \mathrm{~cm}^{2}$ & 7 & 1 & 0.095 & Mann-Whitney U test \\
\hline$>8 \mathrm{~cm}^{2}$ & 45 & 26 & & \\
\hline Followup & Mean, 75.3 months & Mean, 51.2 months & & \\
\hline Local recurrence & 6 & 0 & 0.066 & Chi-square \\
\hline MSTS functional score & $85.3 \pm 5.5$ & $65.9 \pm 4.9$ & $0.008^{*}$ & Student's t-test \\
\hline Complications & 6 & 3 & 0.954 & Chi-square \\
\hline
\end{tabular}

*Statistically significant.

responses to neoadjuvant chemotherapy, and no pathologic fracture. Chemonecrosis was assessed using the grading system of Huvos et al. [14]. More than 90\% necrosis on the histologic sections was considered a good response to chemotherapy. All patients in this series were available for followup at a minimum of 12 months (mean followup in the hyperthermia group, 79 months, range, 12-158 months; mean followup in the amputation group, 95 months, range, 15-142 months).

All patients had radiographs, CT, MRI, and bone scans. With the numbers available, we found no difference in sex between the amputation group and microwave-induced hyperthermia group (12 males and 15 females versus 30 males and 22 females; $p=0.263$ ) (Table 3). We also found no difference in age $(27.5 \pm 8.7$ years versus $31.2 \pm 6.4$ years; $\mathrm{p}=0.586$ ), tumor grade, tumor stage, and tumor size between the amputation group and the microwave-induced hyperthermia group (Table 3). Of the 79 patients, 54 had a needle biopsy and 32 had an incisional biopsy, including those whose needle biopsy was nondiagnostic. We graded the histologic sections based on the biopsy using Broders' classification [1], which has four grades according to the rate of differentiation of the tumor cells. We staged patients using the surgical staging systems of the MSTS [6] and the American Joint Committee on Cancer (AJCC) [24]. Nineteen patients had Stage I tumors and 60 had Stage II tumors.

\section{Surgical Technique}

All patients were evaluated by CT and MRI at the end of each chemotherapy regimen preoperatively to define the edge of the tumor, which was determined at the transition of marrow signal from abnormal to normal. Areas of intermediate signal intensity adjacent to the tumor edge were regarded as part of the tumor and should be included in the ablation area. All 79 patients received two cycles of preoperative neoadjuvant chemotherapy based on a standard protocol which was described in a previous study [17].

Patients treated with microwave-induced hyperthermia were evaluated according to the following criteria: (1) assessment of tumor response or progression as assessed by MRI; (2) distance between the ankle cartilage and the tumor as assessed by MRI of $20 \mathrm{~mm}$ or more, to obtain a bone width margin of $10 \mathrm{~mm}$ and a remaining residual epiphysis of $10 \mathrm{~mm}$, and wide proximal margins on the bone resections [19] (defined as a cuff of $2 \mathrm{~cm}$ to $3 \mathrm{~cm}$ of normal tissue remaining on all sides of the tumor); and (3) a sufficient amount of epiphysis preserved to allow fixation of the osteotomy junction [21]. Intraoperatively, the adequacy of bone resection was evaluated with frozen section biopsy of a tissue sample obtained from the medullary canal of the residual tibia. For all patients who had amputations, the margins were wide (a cuff of $2 \mathrm{~cm}$ to $3 \mathrm{~cm}$ of normal tissue remaining on all sides of the tumor). After surgery, the histologic margins were negative in all patients.

All operations were performed by the same two surgeons (QYF and YZ). The microwave-induced hyperthermia machine we used was the FORSEA (Xinhua Company, Nanjing, China) [9, 10], and the microwave generator frequency is $2450 \mathrm{MHz}$. When microwave-induced hyperthermia was performed (Fig. 1), the main principle was to dissect the tumor with a safe margin as 

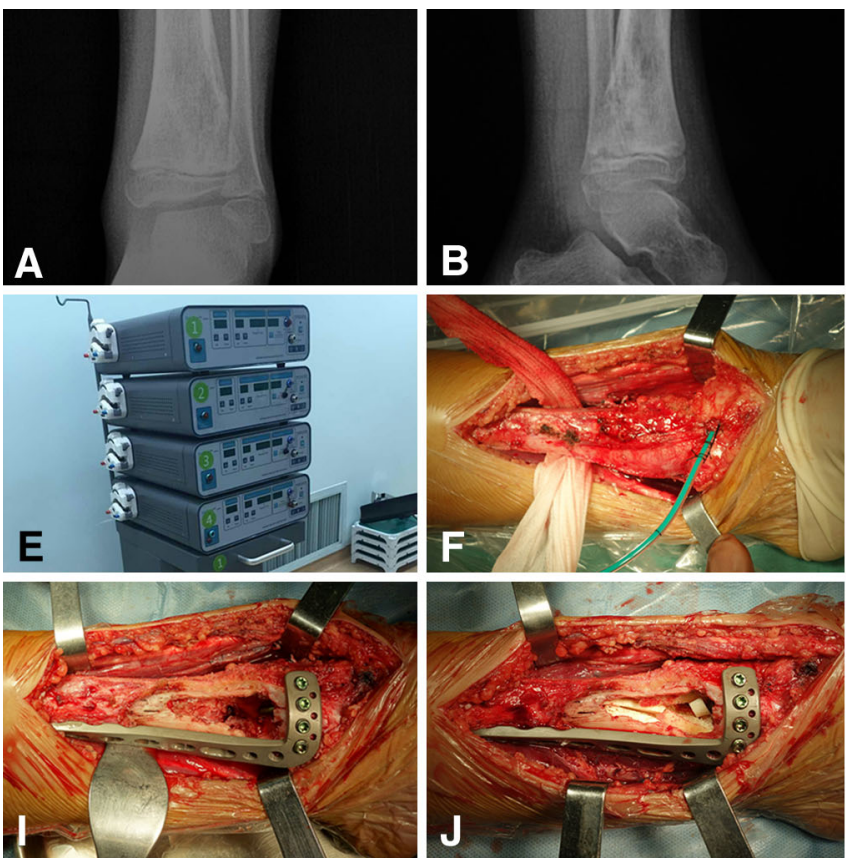

Fig. 1A-L (A) AP and (B) lateral radiographs show an osteosarcoma of the distal tibia. (C) Pathologic examination of the tumor, and (D) bone scans are shown. (E) The photograph shows the microwaveinduced hyperthermia machine. (F) Dissection is shown of the tumorbearing bone from the surrounding normal tissues with a safe margin. (G) A wet gauze is placed between the tumor bone and surrounding

described above, and subsequently perform an en bloc ablation using antenna-guided hyperthermia therapy. The first step was to identify the extent of the tumor and dissect the tumor-bearing bone from surrounding normal tissues with a safe margin (at least $20 \mathrm{~mm}$ width). We usually use the original dissection method of double incisions to obtain adequate exposure (Fig. 1F). This step is very important because it is helps to ensure the entire tumor can be killed by microwave-induced hyperthermia. A heat-isolation pad and wet gauze then were placed between the bone tumor and surrounding normal tissues. Then, one to six antennas were placed in different location of the tumor from different angles, matching the suction one-to-one, according to the shape and size of the tumor to ensure the therapeutic range and the tumor edge could be ablated adequately. Heat output was instant when the antennas were placed, and electromagnetic energy then was delivered to the tumor (Fig. 1G). The tumor was ablated with direct heating while normal soft tissues were protected from overheating. The goal of microwave ablation is to create an ablation zone that extends $1 \mathrm{~cm}$ beyond the tumor boundary at all points with the core temperature of the tumor reaching $85^{\circ}$ to $100^{\circ} \mathrm{C}$ and the normal tissue temperature remaining less than $40^{\circ} \mathrm{C}$ for 15 to 20 minutes. During surgery, a circulating cool saline system was used to protect the surrounding normal tissues, and multiple thermocouples

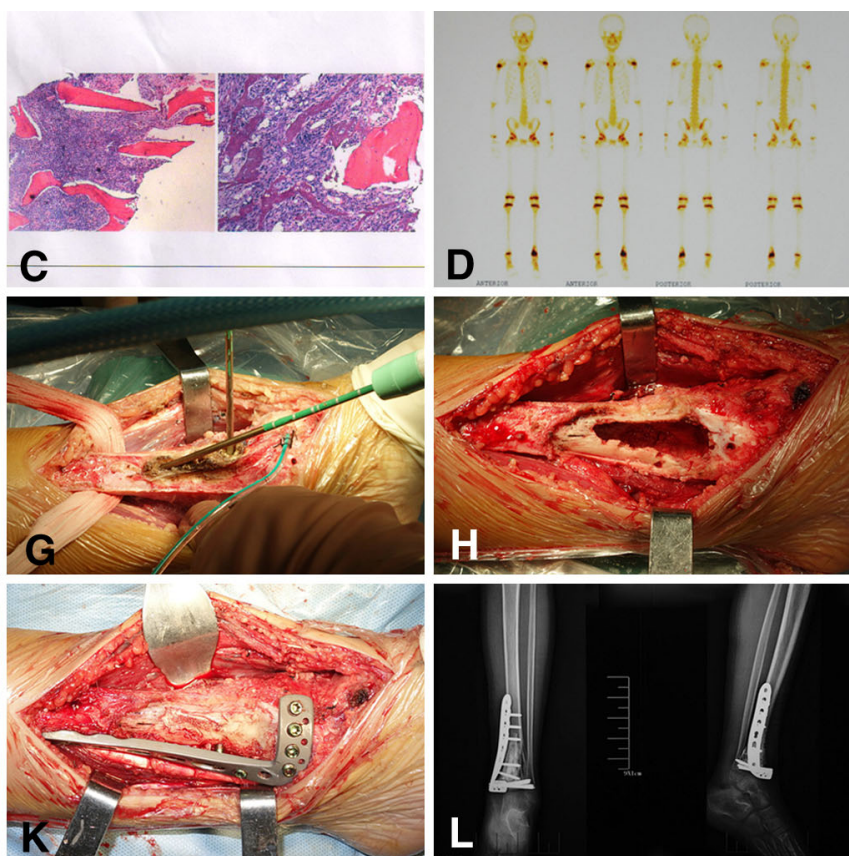

normal tissues and electromagnetic energy is delivered to the tumor bone. (H) The dead or softened tumor is removed or curetted, (I) followed by prophylactic fixation. (J) The defect then is filled with allograft bone, $(\mathbf{K})$ as shown in this image of the mixture of bone cement and allograft bone chips. (L) Postoperative AP and lateral radiographs are shown.

were placed in various critical locations to monitor the temperature. To avoid damaging the joint, outlet piping which was connected with a circulating water pump and the thermocouples were specifically placed in the ankle cavity to keep the articular cartilage and its subchondral bone from overheating. All the tissue blocks were evaluated histologically for tumor hyperthermia necrosis and the histologic examination showed that part of the proximal margins were histologically negative and part of the margins were necrotic. After the dead tumor mass was removed or curetted (Fig. 1H), the reconstruction was performed using a mixture of bone chips and bone cement (Fig. 1I-K) [18]. The normal shape of the tibia was restored and prophylactic fixation was performed if necessary (Fig. 1I-K).

Transtibial amputation was performed as common practice [13].The goals and requirements were resecting the bone $2 \mathrm{~cm}$ to $3 \mathrm{~cm}$ proximal to abnormal bone density, obtaining adequate length of the residual limb, and achieving good soft tissue coverage.

\section{Postsurgery Rehabilitation and Followup}

All patients in both groups were given antibiotics for 72 hours after surgery, and they performed bed exercises until 
wound healing was achieved. A short cast or a brace was used for patients who had microwave-induced hyperthermia until there was radiographic evidence of bone union. Signs of bony union were evaluated by serial sets of plain radiographs [11]. All patients in both groups received postoperative chemotherapy (adriamycin, cisplatin, methotrexate, ifosfamide) [10]).

After discharge from the hospital, clinical and radiographic followups are done every month during the first 6 months, then every 3 months during the next 2 years, and then every 6 months. Chest CT scans were performed to observe pulmonary metastasis every 3 months during the first year and then every 6 months afterward. A bone scan was performed every 6 months during the first year and then every year. All patients have radiographs taken once a year. The MSTS score was used to observe the function of the patients. The status and function of the ankle were specifically assessed clinically and radiologically at followups.

\section{Clinical Outcomes}

Clinical outcomes were assessed by review of clinic notes, supplemented by phone questionnaires, and email where needed. Local recurrence, metastasis, complications, and death were recorded from the patients' files. Complications were graded using the classification described by Dindo et al. [3], which graded the complications at five levels. Followup review and data were sorted and analyzed by three of the authors (KH, NB, TY).

\section{Statistical Analysis}

All values are expressed as mean $\pm \mathrm{SD}$, and all error bars represent the SD of the mean. Student's t test and one-way ANOVA were used to determine significance. Survival rates were estimated using the Kaplan-Meier method. We compared survival between the two groups using a log-rank test. Chi-square test was used to compare complications between the two groups. The mean, SD, and 95\% CI were provided. All statistical tests were two-sided. A probability less than 0.05 was considered statistically significant. Statistical analyses were performed using SPSS Version 17.0 (SPSS Inc, Chicago, IL, USA).

\section{Results}

Survival

With the numbers available, there was no difference in Kaplan-Meier survivorship between the groups. In the limb salvage group, Kaplan Meier survival at 6 years was $80 \%$ (95\% CI, 63\%-90\%), and in the amputation group it was $70 \%$ at 6 years $(95 \%$ CI, $37 \%-90 \% ; p=0.301)$ (Fig. 2). At last followup, six of 27 patients $(22 \%)$ had died in the amputation group and nine of $52(17 \%)$ had died in the microwave-induced hyperthermia group.

\section{Local Recurrence}

With the numbers available, we found no difference in local recurrence (six versus $0 ; p=0.066$ ) between the amputation and microwave-induced hyperthermia groups. Six of the 52 patients who had microwave-induced hyperthermia (11.5\%) (Table 1) had a local recurrence, whereas no patients in the amputation group had a local recurrence. The time to local recurrence was 4 to 18 months after surgery (median, 8.74 months). Two of the six patients were treated with microwave-induced hyperthermia again and four underwent amputations. No patient has had a second local recurrence.

\section{MSTS Functional Score}

However, mean \pm SD MSTS functional scores were higher in patients who had microwave-induced hyperthermia compared with those who had amputations $(85 \% \pm 6 \%$ versus $66 \% \pm 5 \%$; $95 \% \mathrm{CI}$ of the difference, 16.01-23.10; $\mathrm{p}=0.008)$ (Table 3). At latest followup, we observed no evidence of ankle instability, deformity, or degenerative changes of the ankle in any of the patients who had microwave-induced hyperthermia.

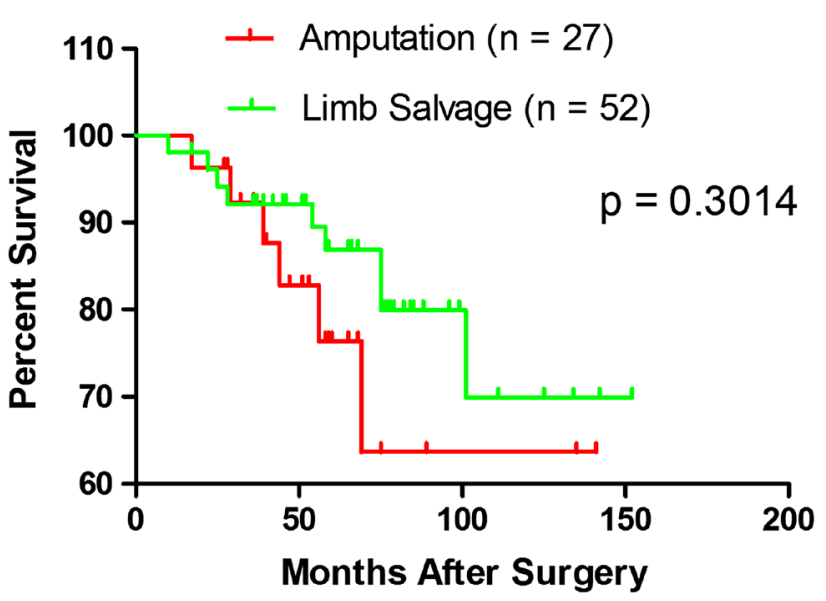

Fig. 2 A graph shows similar (log rank tests, $p=0.3014$ ) survival for patients with distal tibia osteosarcomas treated with microwaveinduced hyperthermia and with amputation. 
Complications

With the numbers available, we found no difference in the proportion of patients experiencing postsurgical complications between the two groups (six of 52 [12\%] versus three of 27 [11\%]; odds ratio, 1.043; 95\% CI, 0.240-4.544; $\mathrm{p}=0.954)$. Complication severity, as graded according to Dindo et al. [3], likewise was not different with the numbers available $(p=0.9983)$. Six of the 52 patients who had microwave-induced hyperthermia (Table 3 ) experienced complications. Two patients experienced delayed union and eventually achieved union (Grade IIIb). One patient experienced fracture and was treated with arthrodesis (Grade IIIb). Two patients had superficial infections (Grade I), which resolved with local dressing changes. One patient had a deep infection (Grade IIIb), which was resolved by irrigation, débridement, and administration of systemic antibiotics.

Three of the 27 patients who had amputations (Table 1) experienced complications. Two patients experienced wound dehiscence and were treated with wound débridement (Grade IIIb). One patient had a superficial infection that resolved with local dressing changes (Grade I).

\section{Discussion}

Below-knee amputation has been regarded as the standard surgical treatment for distal tibia osteosarcoma because of the difficulties in reconstruction when massive bone is lost so close to the ankle [16]. Historically, it has been very difficult to achieve satisfactory oncologic results and function with limb salvage in this anatomic location because of its particular challenges [12, 16, 18]. It has been reported that transtibial amputation provides a low risk of local recurrence and satisfactory function [2]. However, many patients refuse amputation for psychological or social reasons. Microwave-induced hyperthermia has been used with some success for two decades [7, 8]. We believe that the biggest advantage of microwave-induced hyperthermia is that it may relieve the patients of the need to have an amputation. However, to our knowledge, no comparative study has evaluated its efficacy for patients with distal tibia osteosarcoma. We therefore asked whether it would provide (1) improved survival, (2) decreased local recurrence, (3) improved MSTS scores, or (4) fewer complications than amputation in patients with a distal tibial osteosarcoma.

There were some limitations in this study. First, the sample size was relatively small despite this being one of the largest studies reported. This limited our ability to analyze for other factors that might have influenced the oncologic outcomes. Second, this study was a retrospective analysis and the two groups were not randomly selected. That being so, selection bias might have been an issue here. Patients perceived to have a worse prognosis may have been selected to have amputation. However, we tried to apply consistent indications for microwave-induced hyperthermia. In addition, the patients in whom limb salvage was not considered possible (such as those in whom neither the posterior tibial artery nor the dorsalis pedis artery was salvageable) were not included in any group. In general, patients were considered eligible for microwaveinduced hyperthermia if they had an at least $20 \mathrm{~mm}$ available distance from the tumor edge to the articular surface, good clinical and imaging response to neoadjuvant chemotherapy, and no pathologic fracture. Patients not meeting these indications were treated with amputation. However, some patients meeting the indications for microwave-induced hyperthermia were treated instead with amputation or conventional limb-salvage approaches because of the patient's subjective wishes (such as cost, function demand, social recognition). Two patients were unable to afford microwave-induced hyperthermia because of its high price and two other patients had anxiety owing to the possibility of tumor recurrence. Finally, the followup is relatively short. These patients need to be followed for longer periods to ensure that the tumors do not recur and that other complications related to treatment do not become evident. We intend to continue to follow these patients.

With the numbers available, we found no difference in oncologic survival between patients treated with microwave-induced hyperthermia and those who had transtibial amputation for distal tibia osteosarcoma. Other series $[12,16,18]$ have had similar results between limb salvage and amputation for osteosarcoma of the distal tibia. However, the sample sizes in those studies are relatively smaller and comparisons were performed mostly between different types of reconstructions after limb salvage. Amputation is the secondary treatment when there is recurrence or a complication, in most cases.

Likewise, with the numbers available, the treatments were no different in terms of local recurrence, although there were some local recurrences in the microwave-induced hyperthermia group, and we believe that longer followup will be important in these patients. The incidence is relatively higher in other studies of limb salvage $[5,12,16,26]$, because it is difficult to obtain a safe margin resection when good function is desired at the same time because of the proximity of nerves, vessels, and tendons. When microwave-induced hyperthermia was given, the first step was to dissect the tumor-bearing bone from surrounding normal tissues with a safe margin. The distance between the ankle cartilage and the tumor as assessed by MRI was $20 \mathrm{~mm}$ or more to obtain a bone width margin of $10 \mathrm{~mm}$ and a remaining residual epiphysis of $10 \mathrm{~mm}$. The margins of proximal bone resections 
were wide (a cuff of $2 \mathrm{~cm}$ to $3 \mathrm{~cm}$ of normal tissue remaining on all sides of the tumor). In addition, surrounding tissues were fully protected and multiple antennas were inserted in different locations from different angles to ensure the therapeutic range. This could account for some of the observed recurrence benefit of microwave-induced hyperthermia in our series. To the best of our knowledge, there were no local recurrences reported when amputation was performed, which is the same as in our study [5, 15, 18, 28, 29].

Our technique for microwave-induced hyperthermia resulted in improved function compared with transtibial amputation. Function is very important in all operations. However, the unfortunate reality is that better function seems to carry some risk of recurrence $[2,11,14]$. The reason for this is that for better function less tissue needs to be removed which could result in a high risk of recurrence. We also found that the mean MSTS functional scores for the patients who had microwave-induced hyperthermia were better than scores reported in other limb salvage studies [13, 23, 24]. There could be several reasons for this, although all are somewhat speculative. Osteotomy was not used, so the ankle remained intact; this could account for some of the observed functional benefit in this series. Second, we used a mixture of bone chips, cement, and prophylactic internal fixation for reconstruction. This may have facilitated revascularization, which has been confirmed by animal and clinical experiments $[9,15,30]$, and perhaps helped to reduce the likelihood of nonunion, aseptic loosening, and allograft fracture. The maintained intraarticular structures can provide a good osseous bed for reattachment of resected soft tissues, such as muscles and ligaments.

Finally, we did not see an important difference between the treatment groups in terms of major complications. In fact, complications have a relatively high incidence in the distal tibia compared with other locations because of its unique anatomy [15, 19]. Reported complication rates range from $17 \%$ to $92 \%$ for patients having limb salvage treatment $[16,18,27]$. Topping that ranking were infection, allograft fractures, and nonunion, which is similar to our observed results.

Microwave-induced hyperthermia is an alternative treatment for distal tibia osteosarcoma, which in this series showed that it provided improved function compared with transtibial amputation, without any apparent increase in death, local recurrence, or complications. However, these findings should be replicated in larger studies with longer mean followups, and in studies that compare microwaveinduced hyperthermia with conventional limb-sparing approaches.

Acknowledgments We thank Shoufeng Jiao MS, Qunqun Shan MS, Jian Qi MS, Zhaohu Mao MS, Shusen Tan MS, Baolong Wang MS, Changsheng Yang MS, and Zengkun Yang MS (all from the
Department of Spinal Cord Injury, General Hospital of Jinan Military Area Command of Chinese PLA, Jinan, Shandong, People's Republic of China) for technical assistance and helpful discussions.

Open Access This article is distributed under the terms of the Creative Commons Attribution 4.0 International License (http:// creativecommons.org/licenses/by/4.0/), which permits unrestricted use, distribution, and reproduction in any medium, provided you give appropriate credit to the original author(s) and the source, provide a link to the Creative Commons license, and indicate if changes were made.

\section{References}

1. Broders AC. Squamous-cell epithelioma of the skin: a study of 256 cases. Ann Surg. 1921;73:141-160.

2. Campanacci DA, Scoccianti G, Beltrami G, Mugnaini M, Capanna R. Ankle arthrodesis with bone graft after distal tibia resection for bone tumors. Foot Ankle Int. 2008;29:1031-1037.

3. Dindo D, Demartines N, Clavien PA. Classification of surgical complications: a new proposal with evaluation in a cohort of 6336 patients and results of a survey. Ann Surg. 2004;240:205-213.

4. Ebeid W, Amin S, Abdelmegid A, Refaat Y, Ghoneimy A. Reconstruction of distal tibial defects following resection of malignant tumours by pedicled vascularised fibular grafts. Acta Orthop Belg. 2007;73:354-359.

5. El-Sherbiny M. Long term behavior of pedicled vascularized fibular grafts in reconstruction of middle and distal tibia after resection of malignant bone tumors. J Egypt Natl Canc Inst. 2008;20:187-195.

6. Enneking WF. A system of staging musculoskeletal neoplasms. Clin Orthop Relat Res. 1986;204:9-24.

7. Fan Q, Ma B, Guo A, Li Y, Ye J, Zhou Y, Qiu X. Surgical treatment of bone tumors in conjunction with microwave-induced hyperthermia and adjuvant immunotherapy: a preliminary report. Chin Med J (Engl). 1996;109:425-431.

8. Fan QY, Ma BA, Qlu XC, Li YL, Ye J, Zhou Y. Preliminary report on treatment of bone tumors with microwave-induced hyperthermia. Bioelectromagnetics. 1996;17:218-222.

9. Fan QY, Ma BA, Zhou Y, Zhang MH, Hao XB. Bone tumors of the extremities or pelvis treated by microwave-induced hyperthermia. Clin Orthop Relat Res. 2003;406:165-175.

10. Fan QY, Zhou Y, Zhang M, Ma B, Yang T, Long H, Yu Z, Li Z. Microwave ablation of malignant extremity bone tumors. Springerplus. 2016;5:1373.

11. Fan Z, Patel S, Lewis VO, Guadagnolo BA, Lin PP. Should highgrade extraosseous osteosarcoma be treated with multimodality therapy like other soft tissue sarcomas? Clin Orthop Relat Res. 2015:473:3604-3611.

12. Hamada K, Naka N, Murata Y, Yasui Y, Joyama S, Araki N. Prosthetic reconstruction for tumors of the distal tibia: report of two cases. Foot (Edinb). 2011;21:157-161.

13. Hoshi M, Matsumoto S, Manabe J, Tanizawa T, Shigemitsu T, Izawa N, Shi X, Kawaguchi N. Oncologic outcome of parosteal osteosarcoma. Int J Clin Oncol. 2006;11:120-126.

14. Huvos AG, Rosen G, Marcove RC. Primary osteogenic sarcoma: pathologic aspects in 20 patients after treatment with chemotherapy en bloc resection, and prosthetic bone replacement. Arch Pathol Lab Med. 1977;101:14-18.

15. Ji Z, Ma Y, Li W, Li X, Zhao G, Yun Z, Qian J, Fan Q. The healing process of intracorporeally and in situ devitalized distal femur by microwave in a dog model and its mechanical properties in vitro. PloS One. 2012;7:e30505. 
16. Laitinen M, Hardes J, Ahrens H, Gebert C, Leidinger B, Langer M, Winkelmann W, Gosheger G. Treatment of primary malignant bone tumours of the distal tibia. Int Orthop. 2005;29:255-259.

17. Li J, Guo Z, Wang Z, Fan H, Fu J. Does microwave ablation of the tumor edge allow for joint-sparing surgery in patients with osteosarcoma of the proximal tibia? Clin Orthop Relat Res. 2015;473:3204-3211.

18. Liu T, Guo X, Zhang X, Li Z, Zhang Q. Reconstruction with pasteurized autograft for primary malignant bone tumor of distal tibia. Bull Cancer. 2012;99:87-91.

19. Mavrogenis AF, Abati CN, Romagnoli C, Ruggieri P. Similar survival but better function for patients after limb salvage versus amputation for distal tibia osteosarcoma. Clin Orthop Relat Res. 2012;470:1735-1748.

20. Moore DR, Halpern JL, Schwartz HS. Allograft ankle arthrodesis: a limb salvage technique for distal tibial tumors. Clin Orthop Relat Res. 2005;440:213-221.

21. Muscolo DL, Ayerza MA, Aponte-Tinao LA, Ranalletta M. Partial epiphyseal preservation and intercalary allograft reconstruction in high-grade metaphyseal osteosarcoma of the knee. $J$ Bone Joint Surg Am. 2004;86:2686-2693.

22. Natarajan MV, Annamalai K, Williams S, Selvaraj R, Rajagopal TS. Limb salvage in distal tibial osteosarcoma using a custom mega prosthesis. Int Orthop. 2000;24:282-284.

23. Ottaviani G, Jaffe N. The epidemiology of osteosarcoma. Cancer Treat Res. 2009;152:3-13.
24. Printz C. New AJCC cancer staging manual reflects changes in cancer knowledge. Cancer. 2010;116:2-3.

25. Scaglioni MF, Arzi RY, Gur E, Ben Amotz O, Barnea Y, Kollender Y, Meller I, Bickels J, Dadia S, Zaretski A. Free fibula reconstruction of distal tibial defects after sarcoma surgery. Ann Plast Surg. 2015;74:680-683.

26. Shalaby S, Shalaby H, Bassiony A. Limb salvage for osteosarcoma of the distal tibia with resection arthrodesis, autogenous fibular graft and Ilizarov external fixator. J Bone Joint Surg Br. 2006;88:1642-1646.

27. Shekkeris AS, Hanna SA, Sewell MD, Spiegelberg BG, Aston WJ, Blunn GW, Cannon SR, Briggs TW. Endoprosthetic reconstruction of the distal tibia and ankle joint after resection of primary bone tumours. J Bone Joint Surg Br. 2009;91:13781382.

28. Subhadrabandhu S, Takeuchi A, Yamamoto N, Shirai T, Nishida H, Hayashi K, Miwa S, Tsuchiya H. Frozen autograft-prosthesis composite reconstruction in malignant bone tumors. Orthopedics. 2015;38:e911-918.

29. Wong KC, Lee V, Shing MM, Kumta S. Surgical resection of relapse may improve postrelapse survival of patients with localized osteosarcoma. Clin Orthop Relat Res. 2013;471:814-819.

30. Yu Z, Geng J, Zhang M, Zhou Y, Fan Q, Chen J. Treatment of osteosarcoma with microwave thermal ablation to induce immunogenic cell death. Oncotarget. 2014;5:6526-6539. 